\title{
EN TORNO A LA DIMENSIÓN LITERARIA DE VIENTO SECO*
}

\author{
ABOUT THE LITERARY DIMENSIÓN \\ OF VIENTO SECO
}

\author{
ÓSCAR OSORIO \\ Universidad del Valle. Cali, Colombia \\ oscar.osorio@correounivalle.edu.co
}

\begin{abstract}
Resumen: Este artículo propone tres claves de lectura nuevas para aproximarse a Viento seco de Daniel Caicedo: la irrupción de imágenes poéticas en una prosa dominada por el realismo descarnado, la inversión cronológica de los hechos centrales y la compleja estructura del relato. Estos aspectos han pasado inadvertidos para la crítica, que, en general, se ha aproximado a la novela con el prejuicio de su nulo valor literario y su importancia testimonial. El análisis permite concluir que el autor buscó a través de esos procedimientos textuales no solamente la dignidad estética de su obra, sino llamar la atención del lector sobre esa dimensión.
\end{abstract}

Palabras clave: Daniel Caicedo, literatura y violencia, literatura colombiana, novela de la violencia en el Valle del Cauca, narrativas de la violencia.

\begin{abstract}
This article proposes three new interpretation keys in an approach to Viento seco by Daniel Caicedo: the emergence of poetic images in a prose dominated by stark realism, the chronological inversion of the central incidents and the complex structure of the novel. These aspects have been overlooked by criticism which, in general, has approached the novel with the preconception of its invalid literary value and testimonial importance. The analysis allows for the conclusion that the author, through these textual procedures, seeks not only the aesthetic dignity of his work, but also to draw the reader's attention to that aspect.
\end{abstract}

Keywords: Daniel Caicedo, literature and violence, Colombian literature, violence novel in Valle del Cauca, narratives on violence.

Recibido: 15.04.2016. Aceptado: 08.08.2016

* Este trabajo es parte del proyecto de investigación "Novela y violencia en el Valle del Cauca, siglos XX y XXI", aprobada bajo el código CI-4312, en la Universidad del Valle. 
$V$ IENTO SECO (1953) de Daniel Caicedo narra los acontecimientos ocurridos en octubre de 1949, a raíz del proyecto de conservatización de la cordillera Occidental en el Valle del Cauca. Este proyecto político genocida, que fue una estrategia partidista cuyo propósito era imponer una hegemonía conservadora homogeneizando políticamente las poblaciones de esa cordillera, fue organizado por sectores radicales del partido Conservador:

Este es el sentido de la consigna dada por los dirigentes conservadores a "El cóndor" de convertir la Cordillera Occidental en la "cordillera Azul" (...) En octubre de 1949 se llevaron a cabo las masacres y persecuciones liberales de Trujillo, Riofrío, Ceilán, Bolívar, Barragán, Vijes y Yotoco; meses atrás, cuando Borrero Olano no era todavía gobernador, visitó a "El Cóndor" en Tuluá, en compañía del doctor Ramírez Moreno, para legitimar su jefatura de muerte, ganada enfermizamente el 9 de abril con armas, dinero y el respaldo de un sector del Partido Conservador (Betancourt y García, 1990: 126).

La novela focaliza dos hechos de especial trascendencia en esta campaña homicida: la masacre de la Casa Liberal en $\mathrm{Cali}^{1}$ y la masacre de Ceylán ${ }^{2}$. Además de estas matanzas, la última parte se dedica a la acción de las bandas liberales en el norte del Valle y la ilusión del proyecto guerrillero de los Llanos Orientales ${ }^{3}$. La crítica se ha ocupado de examinar la relación de la novela con ese contexto social, señalando insistentemente su carácter

"Algunas conversaciones en torno a un acuerdo bipartidista continuaron a puerta cerrada y el 21 [de octubre] el candidato a la presidencia ofreció la fórmula de un "gobierno mixto para pacificar al país”. Pero al día siguiente, la matanza perpetrada por la policía en la Casa Liberal de Cali, que dejó 24 muertos y 60 heridos, disipó las esperanzas de un arreglo" (Palacios, 1995: 203).

2 "El 27 de octubre fue arrasado Ceylán a bala, fuego y dinamita. En el poblado de San Rafael, la policía fusiló a campesinos liberales y arrojó sus cadáveres al río. Las matanzas dejaron un saldo de 150 muertos en Ceylán y 27 en San Rafael” (Medina, 1990: 52).

3 "La referencia a las estrategias individuales parece mucho menos legítima en los casos en los que, frente al régimen conservador o a sus procedimientos terroristas, se conforman organizaciones de resistencia armada con base campesina que surgen durante el año 1949, y que se implantan muy pronto en numerosas regiones; son muy a menudo de obediencia liberal, aun cuando en ciertas zonas están influenciadas por el partido comunista que, a partir de 1950, exhorta a la "autodefensa campesina” y la pone en práctica principalmente en el sur del Tolima. Estas organizaciones reúnen muchas veces efectivos muy considerables. Las guerrillas de los Llanos Orientales llegaron a agrupar en 1953 cerca de diez mil personas" (Pécaut, 2001: 628). 
testimonial y de denuncia, pero no ha dedicado ninguna atención al asunto de la estructura formal o de sus búsquedas estéticas, como no sea para descalificarlas. Este trabajo se ocupa de estudiar algunos procedimientos a través de los cuales se hace patente la intención autorial de darle al relato de estos sucesos un tratamiento literario e, incluso, de llamar la atención del lector sobre esa dimensión textual.

En Colombia se han producido cientos de novelas en las cuales el tema de la violencia es central. Ello, por supuesto, se debe a que hemos pasado por tres escenarios de violencia generalizada que han dejado millones de víctimas y que han marcado varias generaciones de colombianos. En esta tradición literaria, la novelística sobre la Violencia de los años cincuenta y sesenta es quizá la más prolífica, dejando más de un centenar de obras. En "Anotaciones para un estudio de la novela de la violencia en Colombia" y "Siete estudios sobre la novela de la violencia en Colombia, una evaluación crítica y una nueva perspectiva”, propongo una división de dicha narrativa en cuatro grupos. Viento seco es la más importante y la más conocida del primer grupo, cuyas características describo así: "El hecho histórico prima sobre el hecho literario. Se trata de textos testimoniales y/o de denuncia, en los que la inmediatez de los sucesos, el dolor reciente o la rabia viva, y la urgencia del testimonio difumina la intención literaria. Los personajes son ahogados por la necesidad de la denuncia y los novelistas concentran en ellos todo el dolor y la ignominia, son como un crisol en el que el escritor va vaciando todas las aberraciones e injusticias de la violencia. Algunos de estos escritores entran a la literatura solo una vez para dejar ese testimonio de su experiencia" (Osorio, 2006: 105) ${ }^{4}$. El resultado de esta primacía de lo histórico sobre lo literario y la falta de distanciamiento de los autores de la novelística de este primer grupo generó una literatura con ostensibles deficiencias en su realización literaria. La crítica valoró esta como una mala literatura y ese juicio se extendió a toda la narrativa de la Violencia. Dada la importancia de Viento seco en el ámbito de esta novelística y los errores a que dicho prejuicio ha conllevado a la hora de leerla, una indagación sobre

${ }^{4}$ Nótese que digo "difumina la intención literaria”. Esto no debe entenderse como la supresión del interés del autor por la dignidad estética de su novela, sino de una subordinación de los intereses artísticos a la fuerza arrolladora de las cruentas realidades que testimonia o denuncia. 
la dimensión literaria de esta obra se hace necesaria para empezar a hacer una revisión más rigurosa sobre los alcances de la narrativa de la violencia en Colombia.

García Márquez (1959) afirmó que "quienes han leído todas las novelas de la violencia que se escribieron en Colombia, parecen de acuerdo en que todas son malas y hay que confiar en que estén secretamente de acuerdo con ellos algunos de sus propios autores" (286). Ya había advertido Antonio García (1954) que Viento seco, por su vocación testimonial, prescindía de "refinamientos verbales, elaboración literaria" (19) y Álvarez Gardeazábal (1970) que era "un esfuerzo, desgraciadamente fallido literariamente" (55). Restrepo (1976) desarrolló un poco más la idea de Antonio García (1954) y afirmó que en la novela "se rechaza lo que se consideran sofisticaciones y primores superfluos del quehacer literario, por entendérselos como mecanismos para aprestigiar y maquillar una realidad corrompida y negativa, que el autor busca, por el contrario, mostrar en toda la desnudez de su fealdad y su degradación social y humana" (128). En esa misma dirección, Bedoya y Escobar (1980) plantearon que "a este valor documental se opone la precariedad de la elaboración literaria, que hace de ésta, como de otras muchas novelas sobre la violencia, prácticamente simples colecciones de crónicas de muertes" (43). Pineda Botero (2001) sostiene que "su poca elaboración literaria, la falta de caracterización de los personajes, el lenguaje crudo y sin creatividad la condenan desde la perspectiva literaria" (123). Terao (2003) listó una serie de problemas de construcción argumentales y concluyó que "Viento seco es una obra mal elaborada como novela" (55). Kevin García (2012) la sancionó como una "infortunada realización estética” (114) y señaló, como Terao (2003), algunas de sus fallas más ostensibles.

Antonio García (1954) y Restrepo (1976) encontraron que esa precariedad era el resultado del desinterés y rechazo por estas cosas de la literatura que resultaban superfluas ante el horror de la realidad que sirve de referente a la ficción novelesca. Los demás críticos simplemente desestimaron el valor artístico del texto, pero fue García Márquez (1959) quien acertó en la explicación de las razones de esta falta de tino de las novelas de la Violencia: "Ninguno de los señores que escribieron novelas de la violencia por haberla visto, tenía según parece suficiente experiencia literaria para componer un testimonio con una cierta validez, después de reponerse del atolondra- 
miento que con razón le produjo el impacto" (286). Juan Gabriel Vásquez (2009) llevó al extremo esta argumentación al decir que es precisamente ese parasitismo de lo histórico el que arruina esas novelas de la violencia: "Contar cosas que ya se saben es cometer el pecado de la redundancia, el peor pecado que puede cometer un novelista, el pecado que cometieron los novelistas de la Violencia hace medio siglo" (107). Efectivamente, en el caso de Caicedo, la falta de pericia en la escritura ficcional y la urgencia de la denuncia conllevaron dificultades en la realización de la obra: absurdos argumentales, construcción maniquea y sin dimensionalidad de los personajes, repetición incesante de escenas escabrosas 5 . Sin embargo, es un error concluir a partir de estas precariedades, como lo hacen Antonio García (1954) y Laura Restrepo (1976), la falta de interés del escritor por el estatuto literario de su texto o la renuncia a los "primores" de la literatura. Es evidente en Viento seco el afán testimonial, la necesidad de contar con detalle los sucesos de ese nefando 1949 en Colombia y, particularmente, en el Valle del Cauca, pero con las herramientas de la novela y procurando la dignificación estética del relato.

Esto se hace manifiesto con una rápida mirada a la textura de la prosa, en la que se advierte la necesidad descriptiva propia del testimonio y la vocación realista de Viento seco a la par que el vuelo lírico en la construcción de imágenes de clara intención poética. Efectivamente, la novela está llena de pasajes donde el narrador echa mano de estos recursos, incluso en escenas de un alto contenido de violencia: "Y continuaron la marcha cautelosamente, con los ojos como faros inquietos, y el oído en el viento. $\mathrm{Y}$ el viento aulló, o las voces aullaron en el viento" (52), "Las llamas y el humo eran de distintos colores. Se destacaban algunos penachos blanquísimos y estilizados, cual si las almas que volaban al espacio quisieran aparecer distintas. El aire se quedó quieto, parado" (69), "Acababa de expirar y su alma estaba en ese instante mezclada a la niebla. Y la niebla fue más espesa” (75), "Y sus ojos licuaron la niebla" (76), "La música sonaba. Las almas estaban tristes" (98), "Pasaron el puente vencido por el tiempo, que salta el Cauca de orilla a orilla" (99), "La luna filtraba sus rayos por entre la fronda. Los animales escapaban haciendo crujir la hojarasca. Algunas ramas se movían

\footnotetext{
${ }^{5}$ Veáse: Bedoya y Escobar (1980: 112-114), Álvarez Gardeazábal (1970: 56-57), Terao (2003: 52-53), Kevín García (2012: 117).
} 
como manos. Algunas hojas emitían luces de plata. Los tallos musgosos olían como pomos de perfumes sin tapa" (170-171).

Álvarez Gardeazábal (1970) destacó la inconsistencia de estos registros poéticos: "El lirismo no bien expresado termina por convertirse en un lastre para una novela que se las da de realista" (57). Bedoya y Escobar (1980) también anotaron el desajuste entre las indagaciones poéticas y el realismo escueto de la novela:

El trabajo con el lenguaje denota un distanciamiento problemático entre el autor y la realidad novelada. Esto le resta unidad lingüística a la misma, estilo y tono y por ende el realismo literario es muy limitado. No llega a crear un lenguaje literario adecuado a la historia que cuenta y aunque hay escenas muy poéticas, de gran lirismo e introspección en las que se relaciona el drama humano con los movimientos de la naturaleza, elemento propio y común en toda literatura romántica, hay que señalar que eso no encaja dentro del realismo descarnadamente naturalista de la novela (116).

Es justa esta apreciación. Los recursos poéticos irrumpen abruptamente, generando una sensación de extrañamiento en el lector. Podría afirmarse que resultan impertinentes por varias razones: primero, porque difieren del registro directo de los acontecimientos, que es el tono general de la novela ${ }^{6}$, segundo, porque parecen falseamientos de las escenas mismas que describen; tercero porque son realizaciones poéticas bastante inocentes en sí mismas y en ningún caso, ni siquiera leyéndolos de manera aislada, resultan hallazgos poéticos. Lo que sí evidencian estos recursos líricos, extraños al realismo seco de la novela, es el afán de dignificación estética de la obra. Y es patente que, por esa vía, Caicedo fracasa en su empeño.

Otro elemento que hace patente el interés literario del autor es la inversión cronológica en la datación de los hechos históricos centrales en su diégesis. No obstante que él se obliga, por la condición testimonial y vocación realista que le impone a su texto, a una cierta fidelidad con dichos acontecimientos, invierte la cronología de los mismos: aunque la masacre de la Casa Liberal tuvo lugar el 22 de octubre de 1949 y la de Ceylán cinco

${ }^{6}$ Álvarez Gardeazábal (1970) censuraba como una precariedad de la novela "la poca fluidez de una prosa telegráfica que muchas veces cobra ánimos líricos” (56). 
días después, el 27 de octubre7, en Viento seco ocurre primero la masacre de Ceylán y una semana después la masacre de la Casa Liberal, que se fecha con precisión histórica el 22 de octubre.

En el análisis de esta "imprecisión histórica”, Bedoya y Escobar (1980) afirmaron que hay "disparidad entre varios autores sobre las fechas" (63) y que "lo importante en el caso de la novela no es la precisión cronológica sino la recuperación para la historia de acontecimientos que la censura oficial quiso si no ocultar, sí por lo menos desvirtuar" (63). La conclusión de Bedoya y Escobar (1980) no parece sólida. Las fechas del 22 y 27 de octubre de 1949 están bien documentadas. De hecho, ellos mismos citan el libro de Germán Guzmán y un artículo de la revista Semana en los que se confirman estas fechas. Estos dos trabajos son fiables por su vocación histórica el primero y periodística el segundo. También citan, en apoyo a su argumentación, los textos de Laura Restrepo, Oquist y Montaña Cuellar (equivocados en el año: 1947), Zapata Isaza (impreciso y equivocado en el mes: noviembre), Cardozo (equivocado en el año: 1948); es decir, textos cuyos evidentes errores de datación los desautorizan para una argumentación en torno a la cronología de los hechos. Al final del análisis de estas inconsistencias, Bedoya y Escobar sostienen que "la masacre de la Casa Liberal en Cali ocurrió el 22 de octubre de 1949 y que la matanza de Ceilán fue en octubre del mismo año 49" (70). Los dos textos fiables (Guzmán y Semana) son precisos en las fechas: 22 y 27 de octubre de 1949. Podría plantearse que esta inversión se deba a desconocimiento de parte del escritor o a un descuido cronológico, pero muchos elementos van en contravía de esa hipótesis: la precisión del detalle en la narración de ambos acontecimientos (que da cuenta de un conocimiento preciso de los mismos), la cercanía entre el tiempo de ocurrencia de los hechos y la publicación de la novela (cuatro años), la condición de Daniel Caicedo de ser médico del hospital público San Juan de Dios (adonde llegaron muchos heridos y muertos de esas dos masacres y que, seguramente, lo puso en relación directa con

7 "El 18 de octubre llegaron hasta ellos cincuenta agentes de la policía decomisando cédulas, dinero y hasta algunas aves que las familias tenían consigo. Cuatro días más tarde, un grueso grupo salido de las oficinas del detectivismo se apostó en la salida de la sede liberal y disparó sin piedad contra la muchedumbre (...) A san Rafael siguió Ceilán, el 27 de octubre" (Atehortúa, 1995: 169). 
esas víctimas), la importancia que ambos eventos tuvieron en la ciudad y la región. De hecho, Álvarez Gardeazábal (1970) señaló el impacto de estos sucesos en la literatura colombiana: "La más popular de todas las novelas del período fue esta novela del vallecaucano Daniel Caicedo. La más popular por lo escueto de lo narrado, por tratar dos temas vedados para la prensa de ese entonces, la matanza de Ceylán y el atropello asesino a la casa liberal de Cali donde se refugiaban los exiliados de las montañas. Por ambos sitios pasan una gran mayoría de las novelas de la violencia. Todos mencionan esos dos actos criminales como los cumbres del despotismo que manejaba Colombia. Pero solo Daniel Caicedo se apersona de ellos y en un esfuerzo, desgraciadamente fallido literariamente, une las dos matanzas en la persona de Antonio Gallardo, un habitante de Ceylán que salvado de la masacre de liberales busca refugio en la casa de su partido en Cali” (55).

Dado que Viento seco testimonia y denuncia unos hechos ocultados o desvirtuados por diversos mecanismos de censura estatal, es perfectamente presumible que la decisión de invertir la cronología de los mismos haya obedecido a razones más poderosas. Creo que esta inversión se explica mejor como una decisión determinada por una necesidad narrativa. El diseño argumental de Viento seco se monta sobre una estructura diegética muy básica: un antecedente (inicio): la masacre de Ceylán y el desplazamiento de los protagonistas a un lugar de refugio; un acontecimiento central (nudo): la masacre de la Casa Liberal, que cierra toda esperanza de redención; un consecuente (desenlace): la lucha guerrillera en el norte del Valle y la muerte del protagonista. El programa narrativo, que gira alrededor del protagonista, es preciso: primera victimización: muerte de la familia, desplazamiento y desposesión; segunda victimización: muerte de la esposa, anulación de su condición de hombre y soledad absoluta; tercera victimización: respuesta violenta, traición de Pedro y muerte del protagonista.

La preeminencia de la masacre de la Casa Liberal como suceso central de la novela tiene que ver con su condición de lugar de refugio, pues, la victimización del refugiado es dramáticamente más potente. El ataque a un lugar de refugio y de protección al desterrado es una segunda victimización sobre la víctima, una acción nefanda que genera una reprobación inmediata y sin atenuantes contra los victimarios, y empatía con las víctimas. Como esa indignación es el efecto que el escritor quiere producir en la comunidad lectora, recurre a la inversión cronológica para construir esta doble vic- 
timización. En pro de potenciar el efecto en el lector, el narrador le cede la voz al personaje Roberto (sobreviviente de la masacre de Andinápolis) para que describa en detalle esa matanza y refiera sumariamente otras que llenaban de desterrados la Casa Liberal, enseguida de lo cual relata detenidamente su asesinato allí mismo, junto a otras decenas de refugiados.

La imprecisión en la datación de hechos sobre los que el escritor tenía un detallado conocimiento, además de cumplir con ese propósito narrativo, parecía tener otro objetivo: llamar la atención del lector sobre la factura literaria del texto, sobre su condición novelesca. Sólo este guiño al lector puede explicar por qué sitúa a Gallardo en la masacre de Ceylán (con la consecuente obligación de la inversión cronológica para mantener la estrategia narrativa de la doble victimización) y no en otra de las muchas masacres que habían ocurrido en otros pueblos.

La estructura textual es otro de los mecanismos a través de los cuales Caicedo busca, en primer lugar, la dignificación estética de la novela y, en segundo lugar, llamar la atención del lector sobre esta dimensión. El programa narrativo de Viento seco se desarrolla en una estructura tripartita: la primera parte ("La noche del fuego") tiene dos núcleos diegéticos: en el primero (capítulos 1-4) se cuenta la masacre de Ceylán y se privilegia la descripción detallada de los crímenes perpetrados por los conservadores: (Cap. 1) Antonio y Marcela corren hacia su casa, atacada por chulavitas. La casa está en llamas. Un policía atrapa a Marcela con intención de violarla. (Cap. 2) Antonio lo mata a machetazos. Marcela rescata a su hija de cinco años, María José (que había sido estuprada por los criminales) y ve impotente cómo el fuego consume a sus suegros (José Gallardo y María Antonia Escobar), previamente torturados y amarrados dentro de la casa. Ceylán está sometido al ataque de criminales conservadores. Sólo quedan intactas las casas marcadas con cruces azules. El Chamán defeca sobre sus víctimas agonizantes; el Descuartizador tortura a las suyas y viola a una mujer a quien le ha cercenado los senos y le ha hendido el sexo, y la posee mientras agoniza. (Cap. 3) Mientras Lamparilla y Pájaro Azul prueban su puntería contra teas humanas y Vámpiro chupa la sangre de un hombre, los otros pájaros violan y asesinan sin importar la edad de las víctimas. Los criminales amontonan más de ciento cincuenta sobrevivientes en tres camiones y se van, seguidos por un sacerdote católico que bendice la barbarie. (Cap. 4) Los camiones se detienen y los prisioneros son bajados, torturados y asesi- 
nados, mientras el cura en éxtasis sigue repartiendo bendiciones. Los chulavitas despellejan personas vivas, emasculan, mutilan. La Hiena extrae, asa y come con sus ayudantes el corazón de un hombre (ritual que practica desde hace años para retardar los efectos de la ancianidad). Carcajadas y palabrotas animan la masacre.

En el segundo núcleo diegético de esta primera parte (capítulos 5-7) se narra la huida de Antonio Gallardo, Marcela (su esposa) y Pedro Machado hacia Andalucía y Cali, y se privilegia el relato de las tribulaciones de Antonio y Marcela: (Cap. 5) Antonio y Marcela corren hacia Andalucía buscando auxilio médico para su hija, pero la niña muere a causa de la hemorragia producida por la violación. En Antonio crece la necesidad de vengarse. (Cap. 6) Entierran el cadáver de la niña cerca de un guayacán florecido. En el camino se encuentran con Pedro, el hijo de Carlos Machado, y continúan juntos la huida. Llegan a Andalucía donde ven muchas casas abandonadas. (Cap. 77) El conservador Andrés Castro les ofrece refugio en su casa y luego los lleva a Cali. Antonio no sabe si seguir el sendero de rectitud que ha llevado por treinta años o entregarse a la pasión de la venganza.

La segunda parte ("La noche del llanto") también tiene dos núcleos diegéticos. El primero (capítulos 1-5) continúa el relato de las tribulaciones de los protagonistas: viaje de Antonio, Marcela y Pedro (en compañía de Andrés Castro), su llegada y refugio en la Casa Liberal de Cali, con la ayuda de Cristal: (Cap. 1) En un retén de policía en la entrada a Cali, en Juanchito, los esposan y algunos policías se disponen a violar a Marcela, pero don Andrés soborna al "jefe" y logra la liberación. (Cap. 2) El narrador establece la diferencia entre la policía asesina y el ejército indiferente. Al pasar por las instalaciones de la Fuerza Aérea, don Andrés recuerda que en los Llanos Orientales campesinos amarrados eran lanzados desde los aviones militares y reflexiona sobre "la mala madre" que es Colombia. Llegan a la Casa Liberal, donde se refugian los sobrevivientes de las distintas masacres campesinas. (Cap. 3) Cristal les da su propia comida y los deja descansar para que en el descanso encuentren a Dios. Se acuestan en el piso, amontonados. (Cap. 4) Roberto Gómez cuenta las masacres de Primavera y Andinápolis, un pueblo evangélico, donde acabaron con la población, violaron a las niñas y a las mujeres, a la esposa del pastor Davidson le abrieron el vientre, le sacaron el hijo y se lo pusieron atravesado en un machete sobre su cara. Todos morían en la fe del Señor. A Davidson lo sometieron a te- 
rribles torturas y lo crucificaron ya muerto. Antonio rechaza su fe y niega la existencia de Dios. (Cap. 5) A Marcela le preocupa que los carros fantasmas vayan a matar a su marido mientras busca empleo. Roberto hace un balance de la situación: el propósito de las masacres es garantizar que el presidente conservador (aconsejado por los jesuitas) siga en el poder; el ejército es pasivo; la prensa conservadora tergiversa y los demás periódicos están censurados. Antonio expresa su deseo de unirse a la guerrilla de los Llanos para cobrar sus muertos.

El segundo núcleo diegético de esta segunda parte (capítulos 6-8) se concentra en el recuerdo de las matanzas ocurridas en otros municipios, la masacre de la Casa Liberal, la muerte de Marcela y el lanzamiento del cuerpo de Antonio al río Cauca: (Cap. 6) El 22 de octubre de 1949, el jefe del detectivismo recibe la orden del gobernador y van a la Casa Liberal (a dos cuadras de sus oficinas), cierran las puertas y disparan contra la multitud hasta agotar municiones. Algunos heridos son llevados al San Juan de Dios. Los demás sobrevivientes se reparten entre la policía, el detectivismo y el ejército. Antonio ve en los ojos de Cristal el reflejo del odio que él mismo siente. Roberto Gómez agoniza invocando a Dios. (Cap. 7) Antonio es llevado a la cárcel. Lo torturan y lo meten a un sitio donde hay veintiocho prisioneros. La mayoría están desorejados, porque los chulavitas coleccionan orejas y las ofrecen como mérito para los ascensos. (Cap. 8) Los policías cuelgan a Antonio de una viga y, jugando al "tiro al blanco", lo castran a balazos. Lo dan por muerto, lo echan en un camión lleno de cadáveres y lo lanzan al río Cauca. Recuerda el pasado feliz mientras lucha por su vida en los remolinos del río. El boga Martín Galindo lo rescata de entre los guaduales.

La tercera parte ("La noche de la venganza") también se distribuye en dos núcleos diegéticos: el primero (capítulos 1-3) versa sobre las tribulaciones de Antonio y Cristal, su reencuentro y el viaje al norte: (Cap. 1) Reencuentro de Cristal y Antonio. Desde la pieza de un motel escuchan la ejecución de un hombre y el ruido de un carro fantasma. Se cuentan lo que cada uno vivió después del ataque a la Casa Liberal: el entierro de Marcela, la tortura y castración de Antonio. (Cap. 2) Cristal le cuenta su historia. Su nombre verdadero es Clara Isabel, era maestra en una vereda de Armero y diecisiete policías la violaron uno tras otro. Huyó a su tierra llena de vergüenza, odio y deseos de venganza. En los últimos días ha matado a tres 
policías y planea matar a catorce más, para completar la cifra de violadores. Antonio le dice que tiene intenciones de unirse a las guerrillas de Ansermanuevo y después a las del Llano. (Cap. 3) Viajan al norte. En Zarzal se separan. Antonio llega a Cartago y se contacta con Pablo Ortiz, otro rescatado del boga. Deciden buscar a Emilio Arenas, quien, con treinta hombres, ya ha matado más de cien chulavitas.

En el segundo núcleo diegético de esta tercera parte (capítulos 4-7) se trazan escenas de la vida guerrillera, las muertes originadas en las confrontaciones entre agentes del Estado y la guerrilla, y la muerte de Antonio a manos del traidor Pedro: (Cap. 4) Los dos hombres se incorporan al grupo de Emilio Arenas. Veintitrés policías entran a la hacienda donde se supone que está la guerrilla, pero Emilio les ha preparado una emboscada. (Cap. 5) Sólo se salva un policía que estaba cuidando los caballos. Antonio mata a cuatro policías y se siente bien. Se destaca entre los guerrilleros y se convierte en alguien que solo desea matar. A fines de enero, Tomás, hermano de Cristal, viene y le cuenta que ella envenenó a catorce policías y se envenenó ella. Se salvaron tres policías. Emilio es asesinado. Luis, su hermano, es elegido líder de la guerrilla. (Cap. 6) Pedro lleva a Luis a una emboscada y un teniente lo asesina. Ascienden a Pedro por esa acción. El narrador cuenta la historia de Pedro: después de la masacre en la Casa Liberal duerme en la oficina de un jefe político homosexual, quien lo recomienda al detectivismo. Antonio es elegido jefe del grupo. (Cap. 7) Es marzo y la persecución arrecia sobre el grupo guerrillero y afecta a los campesinos de la zona. Antonio decide irse para unirse a la guerrilla de los Llanos y encomienda a Pedro y a Pablo para que preparen el viaje. Cuando se reencuentra con Pedro para irse, este lo mata a balazos. En la agonía, Antonio escucha una voz amada y le dice: "voy...".

Esta apretada síntesis muestra el cuidadoso diseño de Viento seco: la novela se estructura en tres partes, cada una de las cuales está dividida a su vez en dos núcleos diegéticos: I: (1-4), (5-7); II: (1-5), (6-8); III: (1-3), $(4-7)^{8}$. Esto constituye una simetría estructural, que se refuerza con la distribución de los capítulos: la primera parte tiene siete capítulos, la segunda ocho y la tercera siete: I: 7, II: 8, III: 7. Esto es: 7-8-7. La simetría se per-

\footnotetext{
${ }^{8}$ Usaré las siguientes convenciones: números romanos para indicar las partes; entre paréntesis para los núcleos diegéticos; números arábigos para los capítulos.
} 
fecciona con la distribución de los capítulos en los núcleos diegéticos: en la primera parte, el núcleo 1 tiene 4 capítulos y el 2 tiene 3; en la segunda parte, el núcleo 1 tiene 5 capítulos y el 2 tiene 3 ; en la tercera parte, el núcleo 1 tiene 3 capítulos y el 2 tiene 4. Es decir, la organización de los núcleos diegéticos se rige por una distribución simétrica que invierte la cantidad de capítulos que los constituyen en las partes 1 y 3 . El esquema que rige esta construcción simétrica es el siguiente: I: $4+3$, II: $5+3$, III: $3+4$.

En lo atinente a los núcleos diegéticos, los correspondientes a los capítulos 1 a 4 de la primera parte, 6 a 8 de la segunda y 4 a 7 de la tercera constituyen una línea narrativa que se ocupa de las acciones de los pájaros y chulavitas conservadores contra la población liberal (incluidos, en la última parte, las acciones de las autodefensas liberales); los correspondientes a los capítulos 5 a 7 de la primera parte, 1 a 5 de la segunda y 1 a 3 de la tercera constituyen otra línea narrativa, que se ocupa de las tribulaciones de las víctimas liberales. La novela está construida sobre una estructura paralelística, según la cual la línea A privilegia las acciones criminales de los victimarios y la línea B las tribulaciones de las víctimas. El siguiente esquema describe esta estructura: A: I (1-4), II (6-8), III (4-7); B: I (5-7), II (1-5), III (1-3). A cada línea narrativa le corresponden 11 capítulos, que, además, se distribuyen con una simetría perfecta: la línea A tiene cuatro capítulos en la primera parte, tres en la segunda y cuatro en la tercera; la línea $\mathrm{B}$ tiene tres capítulos en la primera parte, cinco en la segunda y tres en la tercera. Esto es: A: 4-3-4; B: 3-5-3.

La elaborada estructura de la novela se rige por el siguiente esquema:

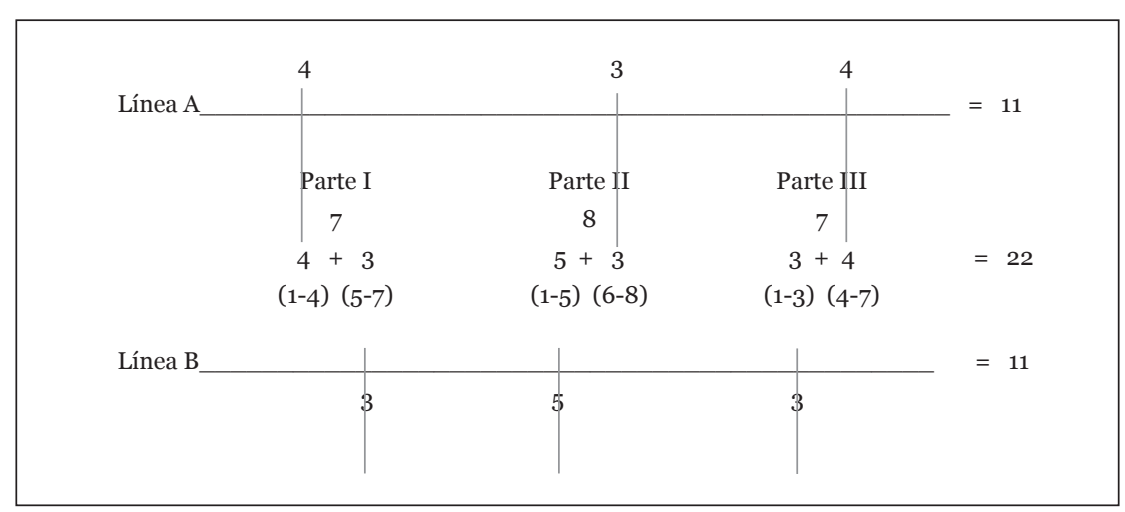


Ahora bien, cada una de las tres partes está precedida por epígrafes de procedencia religiosa, que tienen funciones muy importantes, relacionadas con los contenidos mismos de cada parte y con la dimensión moral que enmarca la lectura de los acontecimientos que hace la novela9. Para este análisis, interesa el primero, tomado de Lamentaciones (atribuido a Jeremías), pues el llamado a este texto bíblico tiene profundas implicaciones en el diseño estructural de Viento seco. Lamentaciones es un conjunto de cinco poemas organizados según la siguiente estructura: los poemas 1, 2, 4 y 5 tienen 22 versículos; el poema 3 tiene 22 estrofas de 3 versículos. Es decir, está construido sobre una estructura simétrica de 22 versículos en los poemas de los extremos y 22 estrofas (de 3 versículos) en el poema de la mitad: I: 22, II: 22, III: 22 (3), IV: 22, V: 22.

El llamado intertextual a Lamentaciones, construida sobre un diseño simétrico con unidades de 22, en una novela que se estructura, con un diseño simétrico, en 22 capítulos, es un potente llamado al lector para que se detenga en la compleja elaboración estructural del texto. Infortunadamente, ni los lectores ni la crítica han examinado esta arquitectura ni han revisado los diversos mecanismos textuales a través de los cuales el autor procuró dignificar estéticamente su testimonio y su denuncia, pues se acercaron a la novela contaminados por el prejuicio de su precaria condición literaria. Sin embargo, la estructura simétrica, el intertexto de Lamentaciones, los numerosos pasajes de intención poética, la inversión cronológica de los acontecimientos centrales, el uso de epígrafes que orientan el sentido de lo narrado acreditan a un escritor consciente de su escritura y preocupado por la dimensión estética de su texto. No parece adecuado, entonces, reducir Viento seco a un registro morboso de la barbarie. La novela tiene fallas de todo orden, pero estas no se deben al desinterés o rechazo de indagaciones propiamente literarias sino a las limitaciones propias de un novelista sin experiencia. Daniel Caicedo era un médico urgido de dejar constancia de las atrocidades que se estaban dando en la región y en el país y echó mano de la literatura para narrar estos hechos, pero evidentemente no tenía la pericia suficiente, ni el distanciamiento necesario. No obstante

\footnotetext{
${ }^{9}$ En el texto "Proselitismo y violencia en Viento seco" analizo las funciones de estos epígrafes.
} 
esto, los ostensibles esfuerzos por darle dignidad literaria a su trabajo no son deleznables y no deberían seguir pasando inadvertidos por la crítica.

\section{Referencias}

Álvarez Gardeazábal, G. (1970). La novelística de la Violencia en Colombia. Monografía de grado. Cali: Universidad del Valle.

Atehortúa Cruz, A. L. (1995). El poder y la sangre. Las historias de Trujillo (Valle). Bogotá: Cinep - Universidad Javeriana.

Bedoya, L. I. y Escobar, A. (1980). La novela de la violencia en Colombia. "Viento seco" de Daniel Caicedo - una lectura crítica-. Medellín: Ediciones Hombre Nuevo.

Betancourt D. y García, M.L. (1990). Matones y cuadrilleros. Origen y evolución de la violencia en el occidente colombiano, 1946-1965. Bogotá: Tercer Mundo Editores.

Caicedo, D. (1954). Viento seco. Buenos Aires: Editorial Nuestra América.

García, A. (1954). La novela realista frente al drama colombiano (prólogo-ensayo). En D. Caicedo, Viento seco (pp. 13-43). Buenos Aires: Editorial Nuestra América.

García, K. A. (2012). Aciertos y desaciertos de la novelística de la violencia en Colombia. Análisis en las obras Viento seco, El día del odio y El día señalado. Nexus, 12, 112-132.

García Márquez, G. (1959). Dos o tres cosas sobre la novela de la violencia en Colombia. En Obra periodística (1983: 285-314), Vol. 6. Bogotá: Oveja Negra.

Medina, M. (1990). La violencia en Colombia: inercias y novedades 1945-1950, 1985-1988. Revista Colombiana de Sociología (Nueva Serie), I, 1, 49-75.

Osorio, O. (2006). Siete estudios sobre la novela de la violencia en Colombia, una evaluación crítica y una nueva perspectiva. Poligramas, 25, 85-108.

Palacios, M. (1995). Entre la legitimidad y la violencia. Colombia 1875-1994. Bogotá: Editorial Norma S.A.

Pécaut, D. (2001). Orden y violencia. Evolución sociopolítica de Colombia entre 1930 y 1953. Bogotá: Norma.

Pineda Botero, Á. (2001). La novela colombiana, 1934-1985. Medellín: Eafit.

Restrepo, L. (1976) Niveles de realidad en la novela de la 'violencia colombiana'. En M. Cárdenas (ed.), (1985), Once ensayos sobre la violencia (pp. 117169). Bogotá: Cerec - Centro Gaitán.

Terao, R. (2003). ¿Ficción o testimonio, novela o reportaje?: la novelística de la violencia en Colombia. Contexto (segunda etapa), 7, 9, 37-59.

Vásquez, J. G. (2009). El arte de la distorsión. Bogotá: Alfaguara. 